\title{
El Código Penal alemán (Das deutsches Strafgesetzbuch) The german Criminal Code (Das deutsches Strafgesetzbuch)
}

\author{
Miguel Ángel Cobos Gómez de Linares \\ Universidad Complutense de Madrid \\ cobgommi@der.ucm.es
}

Recibido / received: 10/03/2018

Aceptado / accepted: 12/03/2018

DOI: https://doi.org/10.20318/eunomia.2018.4173

\section{Prólogo y advertencias preliminares}

I.

En primer lugar, habría que justificar el porqué de la decisión de traducir el StGB. Desde los años 50 han viajado penalistas españoles a Alemania para formarse, de ahí, y de la propia calidad, en general, de la literatura jurídico-penal en alemán proviene la enorme influencia del Derecho penal alemán en el español. Es cierto que también se ha producido, en menor medida, la visita por penalistas españoles a Universidades italianas con la misma finalidad. No obstante, en España no se han llevado a cabo traducciones ni del Código Rocco ni del StGB, seguramente porque quienes no manejan el alemán o bien tampoco tienen interés en la doctrina de ese país o se inclinan por conocer mejor la italiana, o bien, en cuanto a este último caso, porque el Código italiano adolece de una estructura y de unas instituciones francamente anticuadas que lo hacen poco atractivo, no así la doctrina italiana, en general bien considerada en España. En uno y otro caso, quienes conocen el respectivo idioma consultan directamente la legislación penal sin echar mano de traducciones.

No obstante, en Hispanoamérica la situación es distinta pues el número de estudiosos del Derecho penal que han hecho estancias en Alemania o Italia es mucho menor, de manera que el interés y la demanda de textos traducidos quizá sea mayor que en España. En cualquier caso, sea pensando en el público español o en el hispanoamericano, lo cierto es que los operadores jurídicos no estrictamente universitarios sin duda están interesados en conocer qué se dice en la legislación alemana acerca de las instituciones penales de dicho país, sobre todo porque la doctrina alemana sí ha llegado a abogados y jueces a través de, precisamente, las traducciones fundamentalmente, pero no solo, de manuales de este país desde hace ya muchos años. Por otro lado, el método utilizado por todos los investigadores del Derecho penal en España es sin excepción el comparativo, de ahí que el uso de 
legislación y doctrina alemanas sea constante, y de ahí también que a quienes no dominan la lengua de Binding, Hassemer o Roxin les interese en gran medida conocer su obra, pero también el Código penal que ellos, o al menos estos dos últimos, interpretan. Esta razón y la indudable capacidad generadora de inquietudes y proyectos del Profesor Álvarez García están detrás de esta traducción, así que justo es dejar claro que suya fue la idea, y que inmediatamente acepté el encargo por las razones que expuse más arriba, bien consciente de las dificultades, retos y la responsabilidad que implica asumirlo. Por último, al Profesor Ventura Püschel se debe la sugerencia de coordinar, siquiera de manera sucinta, el texto alemán traducido con el Código Penal español, y así se acogió esta idea, como más arriba se ha expuesto con la finalidad de hacer lo más útil posible el texto traducido. Por su parte, Joseba García Celada, quien colaboró eficazmente con Álvarez García y conmigo en la traducción de textos italianos destinados a la elaboración de un artículo sobre terrorismo que escribimos en 1981 (y donde se adelantaba con claridad la construcción de lo que luego se ha denominado el "Derecho Penal del Enemigo"), ha vuelto después de muchos años a repetir experiencia con la traducción italiana de una obra de Carl Schmidt recientemente publicada en esta misma Revista, y ahora vuelve por derecho propio a formar parte de este grupo de trabajo sui generis, constituido para dar seguimiento a la presente traducción del StGB.

II.

A la pregunta de qué caracteres encierra el StGB, solo puede responderse exponiendo brevemente las vicisitudes históricas que lo han acompañado, y debiendo tenerse en cuenta que a ello se responde con largueza en Manuales, Tratados y Comentarios al StGB. Por todo ello, veamos muy sucintamente cuáles han sido éstas, sin ofrecer una evolución histórica más propia de un Manual alemán, o de un Comentario del StGB, y permítaseme acompañar esta exposición con referencias al Código penal español.

Como se advierte nada más abrir un StGB, la versión vigente encuentra su origen en el texto de 1871, el cual, como es inevitable, ha sufrido múltiples reformas hasta la actualidad. En lo que aquí interesa, creo que hay que destacar tres momentos especialmente importantes en su larga vida, a partir de los cuales puede explicarse mejor el interés para el mejor conocimiento e interpretación del Código penal español. En primer lugar, el StGB actual se promulga no llega a cinco meses después de la proclamación de la unidad alemana. Es significativo que casi a continuación de unificarse el país se considere absolutamente necesario promulgar un Código penal. Lógicamente, la rapidez stricto sensu debe atribuirse a coincidir en gran medida con el Código penal prusiano, vigente para la "Unión alemana del Norte" (Norddeutscher Bund) que precedió a la unificación de los Estados alemanes tras la Guerra Francoprusiana, la pruso-danesa por Schleswig y Holstein, y finalmente la pruso-austríaca, consecuencia de la anterior. Disuelta la federación Austro-prusiana, se funda la ya mencionada Unión alemana del Norte, y finalmente el II Reich, tras unirse los Estados del Sur, Baden, Würtemberg y Baviera. Se trataba de un StGB de corte autoritario, como el Código que le sirvió de base, en el que la pena de muerte jugó un papel muy importante, hasta el punto de que fue empeño personal de Bismarck su mantenimiento. Nuestro Código penal también ha sido casi siempre uno autoritario, ya fuera per se, ya por su rechazo a uno anterior que tuviera caracteres liberales habiéndose decidido aplicar una legislación "más dura", como sucedió con la vuelta de Fernando VII al poder y la derogación del Código de 1828, de tintes liberales, y la aplicación de la Novísima Recopilación.

En Alemania, durante la República de Weimar, la inestabilidad política causada por los intentos de insurrección tras la revolución de 1917, el enorme peso 
de las indemnizaciones de guerra tras su final en 1918 (aunque también fueron enormes las impuestas a Francia tras la guerra franco-prusiana), los levantamientos de organizaciones de militares derechistas, el creciente poder de las patronales de grandes industriales que apoyaban a organizaciones de extrema derecha, se hizo imposible, en lo que a la materia penal interesa, que llegaran a buen fin las reformas que de manera temprana ofreció -entre otros- el proyecto de reformas del StGB liderado por el entonces Ministro de Justicia Gustav Radbruch en 1922, que, bajo los postulados de la Escuela Moderna, incluían la abolición de la pena de muerte, la reducción de la aplicación de penas privativas de libertad, especialmente de las más cortas a favor de la multa, y en general una drástica aminoración del pensamiento retributivo frente al preventivo (proyecto que, tras la Segunda Guerra, sirvió de base a la elaboración del Proyecto Alternativo de 1966). En 1923 se produjo el golpe de Estado de Hitler en Múnich, sofocado con el envío de tropas y la colaboración de la Policía no sin dificultades, sin que haya quedado claro si colaboró o no activamente en el mismo el propio Comisario General del Estado (Generalstaatskommissar) en Baviera, von Kahr. En 1930 cae definitivamente la República, fuertemente debilitada por la crisis económica de 1929 y el fortalecimiento de la derecha militarista y nacionalista con su salmodia de necesidad de un espacio vital (Lebensraum) para Alemania, el rechazo al Tratado de Versalles, el peligro del comunismo, autarquía económica para librarse de la crisis y, en suma, lucha contra la democracia socialliberal que representó la República de Weimar. Buena muestra del éxito ultranacionalista fueron las dos elecciones de 1932 en las cuales venció el partido nazi, si bien sin suficiente mayoría parlamentaria. En cualquier caso, la sociedad alemana estaba ya plenamente filtrada por las demostraciones de poder y de la organización militar del partido nazi NSDAP (Partido nacionalsocialista de los trabajadores alemanes).

En 1936, tras haber formado Gobierno Hitler en 1933, ve la luz un Proyecto nazi de Código penal patrocinado por Gürtner, que por el comienzo de la II Guerra Mundial no llegó a promulgarse. En el fondo de este Proyecto, y del "Derecho" nazi, se sitúa como eje de la intervención penal el "sano sentir del pueblo" (gesundes Volksempfinden) que, por supuesto, se genera a través de la voluntad de los dirigentes de zona del Partido (Gauleiter). Durante el tiempo que duró el nazismo se multiplicaron los tipos que aparejaban la pena de muerte, y se llegaron a ejecutar, solo formalmente, 12.000 sentencias capitales, frente a las 183 llevadas a cabo de entre 1141 sentencias durante la República de Weimar ${ }^{1}$. Tras la guerra, con la ocupación de los aliados, y la promulgación de la Ley Fundamental de Bonn en 1949, se abole la pena de muerte.

En España, con la vuelta de la democracia a nuestro país por la proclamación de la Segunda República en 1931, se devuelve la vigencia al Código de 1870 hasta la promulgación, ya en 1932, del Código de la II República que no era más que una adaptación de aquél. Tras el golpe de Estado militar y la derrota de la Segunda República en la Guerra Civil con la ayuda imprescindible de los ejércitos italiano y alemán, se produce la aplicación de un "Derecho" de excepción con las Leyes de Seguridad del Estado de 1941, de Represión de la Masonería y el Comunismo de 1940, y otras promulgadas en los años siguientes, con los efectos de una dura represión para cualquier conducta con implicaciones políticas no afectas al nuevo régimen, además de los numerosos y sumarios juicios a civiles y militares

\footnotetext{
${ }^{1}$ Según C. Meyer-Kretschmer, "DIE ENTWICKLUNG DES DEUTSCHEN STRAFGESETZBUCHES”, en http://www.juraindividuell.de/kategorie/rechtsgeschichte/. Más adelante mantiene que en los últimos años de la guerra se produjeron entre 20.000 y 33.000 Sentencias de pena de muerte y que se habría ejecutado el $89 \%$ de las mismas.
} 
republicanos con fusilamientos, largas penas de prisión, y destierros. En 1944 se promulga un Código penal refundido con intervención principal de Cuello Calón, en contraste con la altura de juristas como Jiménez de Asúa o Antón Oneca en el de 1932, en el que se incluyen las numerosas leyes penales posteriores al fin de la guerra, por las que se restituye la pena de muerte o el delito de adulterio, ausentes en el Código de 1932, que se prolonga con algunas reformas de cierto interés como la ubicación de la pena de reclusión mayor como alternativa a la de muerte que no se constituía así como pena única.

En segundo lugar, y para no alargar mucho más esta breve exposición, puede resumirse que la más importante reforma en el StGB se produjo desde 1962, con amplios estudios y debates para la confección de un nuevo StGB que no vería la luz hasta 1975. Debe destacarse la no menos importante labor de la oposición política en torno al Proyecto alternativo, promovido por el SPD en el que tuvo una intervención especialmente relevante Claus Roxin. Piénsese que desde los primeros años cincuenta y gracias al personal empeño del Fiscal Fritz Bauer se persiguió a muchos criminales nazis que hasta entonces habían hecho vida normal, incluso con altos cargos en la Administración alemana o aliada. Tenía aquí vital importancia la consideración de los acusados como autores, en alguna de sus modalidades, o como cómplices, pues los plazos de prescripción diferían considerablemente y ello conducía a que muchos delitos se considerasen prescritos, además de la atenuación obligatoria para los cómplices. Roxin defendió la tesis de la autoría mediata de muchos de estos criminales, que en principio no se acogió por el Tribunal Supremo, hasta que finalmente se aceptó y pudo aplicarse a un buen número de acusados de horrendos crímenes en los campos de exterminio. En general, en la reforma que culminó en 1975, aún sin un nuevo StGB, es destacable la reelaboración completa de la Parte General, la ausencia de la pena de muerte, la eliminación de las penas de prisión inferiores a seis meses, o de la persecución de la homosexualidad.

En tercer lugar, con posterioridad y hasta hoy, se han incluido figuras delictivas en ocasiones nuevas, como es el caso de la financiación ilegal de Partidos Políticos, o se ha actuado legislativamente en materia de drogas, medio ambiente, delitos relacionados con el uso de ordenadores, terrorismo, y en general, al compás del surgimiento o el recrudecimiento de ciertas formas de delincuencia, se ha puesto al día la legislación penal alemana, con reformas del Código penal o con leyes penales especiales. Es destacable, por otro lado, que la anexión, o reunificación, según se mire, de la DDR no supuso ningún cambio en el StGB.

En España, se siguió también un largo proceso de reformas desde la promulgación de la Constitución de 1978, pues ya en 1979 se confeccionó un Anteproyecto de nuevo Código penal, que se convirtió en Proyecto en 1980 pero que no culminó con éxito su andadura. De forma parecida a lo ocurrido en Alemania en la década de los setenta, se produjo en España en los 80, junto al Proyecto del Gobierno, un verdadero Proyecto Alternativo en torno al Grupo Parlamentario Comunista del Congreso de los Diputados que constituyó un extraordinario documento de trabajo elaborado por los mejores penalistas del momento. Sin embargo, por las lógicas vicisitudes políticas no se promulgó el nuevo Código penal hasta 1995, un verdadero Código penal de la democracia, pues, a pesar de los defectos que inevitablemente puedan señalarse, la oposición conservadora del momento no votó en contra del Proyecto del Gobierno, únicamente se abstuvo.

III.

A las muchas dificultades que una traducción puede presentar, la de una ley añade la del establecimiento más claro posible de la línea divisoria entre la traducción y la 
interpretación. No he podido seguir aquí los consejos de ese hombre del Renacimiento que es John Berger, cuando afirma que "la verdadera traducción no es un affaire binario entre dos lenguas sino uno triangular. El tercer punto del triángulo sería lo que subyace tras las palabras del texto original antes de que fuera escrito. La verdadera traducción exige un retorno a lo preverbal" (Berger, 2016: 4). Participo de su opinión, en cuanto que referida sin duda a la traducción literaria. Es curioso que el Derecho y un idioma sufran, o gocen, de la necesidad de ser interpretados cuando se aplican a la práctica diaria. Por un lado, hay que hallar el significado de la palabra o frase incluyendo su interpretación, lo que hay tras las palabras, cuando sea necesario, para que se entienda. Por otro, puede surgir la duda acerca del significado que tiene para el Derecho el término empleado. Al afrontar la traducción de textos jurídicos se plantea precisamente si, por ejemplo, traducir "Tat" por "Hecho", o por Supuesto de hecho" o por "Tipo". Las opciones son, o ceñirse a la palabra en su acepción más común, u optar por elevarse del uso común del lenguaje y usar un término más técnico, pues al fin y al cabo es dudoso que un lego esté interesado en leer la traducción de un Código penal. En cualquier caso, hay que respetar al máximo la letra de la ley, y aquí vuelvo al principio: hay que ser muy cuidadoso a la hora de plasmar un significado para que quede clara la línea divisoria entre traducir e interpretar.

Creo que, cuando de leyes se trata, tenemos la obligación moral de acercarnos a la literalidad todo lo que la claridad del significado permita. Creo que es muy importante, por ejemplo, que cuando en el StGB se usa el término "hecho", se traduzca así, y no por "tipo" que es el término más usado sin duda en España en materia penal, para ser lo más fieles que sea posible al texto original, lo cual es tan obvio que no debieran exigirse más explicaciones. Por otro lado, a veces uso distinta traducción para el mismo término como cuando traduzco "decisión" o "acuerdo" para referirme a la resolución o al acto de resolver un Juez sobre la imposición de una medida, como confiscar un bien. El problema radica en que, por el contexto, a veces, "acuerdo" suena a que ha habido una composición entre partes, como ocurre cuando hay un reconocimiento de los hechos y la participación en los mismos con el fin de obtener una modificación, con rebaja, de las conclusiones del Fiscal. En esos casos de posible confusión me decanto por "decisión" pues se trata únicamente de lo que el Juez "decide", como por otro lado es lo normal en Derecho penal, con la excepción procesal a la que acabo de referirme.

Como se aprecia inmediatamente, se trata de un texto en el que junto al traducido se incluye el original, aunque con un tamaño de letra menor para evitar que el texto acabe siendo un monstruo inmanejable. Con ello pretendo que esta obra sea útil no solo para quienes no manejan suficientemente el alemán, sino también para quienes, teniendo un buen conocimiento del alemán, quieren manejar un texto en español simplemente porque es más rápido y cómodo su uso, pero a la vez quieren cotejar el texto con el original para asegurarse de que la traducción es fiel, o que encuentra el sentido que uno busca.

Por último, la traducción de la Parte General del StGB no es una opción o alternativa frente a la de la Parte Especial, pero tiene natural preferencia. Sin duda esta última alberga un considerable interés, pero, dado el enorme desarrollo e importancia de la elaboración por la doctrina alemana de la Parte General desde hace casi un siglo, es sin duda la más interesante y útil a la hora de interpretar las instituciones del Derecho penal; además de que, y como su propio nombre indica, la "parte general" es aplicable a cualquiera de las figuras de toda la Parte Especial.

Espero que este trabajo sea útil y sirva al práctico del Derecho penal para obtener ideas y posibles soluciones reales a casos reales, y quizá también al teórico, 
para entender de dónde provienen muchas de las instituciones del Derecho penal que podemos ver en nuestro Código.

\section{Bibliografía}

BERGER, J. (2016), Confabulations, Penguin-Random House, Reino Unido 


\section{Traducción de los artículos 1 a 12 del Código Penal alemán}

\author{
Strafgesetzbuch \\ Ausfertigungsdatum: 15.05.1871 \\ (RGBI. 1871 S. 128-203) \\ "Strafgesetzbuch in der Fassung \\ der Bekanntmachung vom 13. \\ November 1998 (BGBI. I S. 3322), \\ das zuletzt durch Artikel 1 des \\ Gesetzes vom 23. Mai 2017 (BGBI. \\ I S. 1226) geändert worden ist"2
}
Dieses Gesetz tritt am 1. Juli 2017 in Kraft

\author{
Allgemeiner Teil \\ Erster Abschnitt. Das Strafgesetz \\ Erster Titel. Geltungsbereich
}

\section{§1 Keine Strafe ohne Gesetz}

Eine Tat $^{3}$ kann nur bestraft werden, wenn die Strafbarkeit gesetzlich bestimmt war, bevor die Tat begangen wurde.

\author{
Código penal alemán 4 \\ Fecha de publicación: 15.05.1871 \\ (RGBI. ${ }^{5} 1871$ S. $128-203$ )
}

"Código penal en la versión de 13 de noviembre de 1998 (BIGBI. I S. 33226) modificado por última vez por el Artículo 1 de la Ley de 23 de mayo de 2017 (BGBI. I S. 1226)"

\section{$\S 1$ No hay pena sin ley}

Solo se podrá penar un hecho si su punibilidad estaba prevista antes de que el hecho se cometiera ${ }^{8}$.

\footnotetext{
2 Artikel 1 - Dreiundfünfzigstes Gesetz zur Änderung des Strafgesetzbuches - Ausweitung des Maßregelrechts bei extremistischen Straftätern (53. StGBÄndG k.a.Abk.).(Artículo 1 de la $53^{a}$ Ley de modificación del CP. Ampliación de la regulación de medidas para autores extremistas de delitos).

${ }^{3}$ Se ha optado por traducir literalmente "Tat" por "hecho" pues a menudo se utiliza el término "Straftat" (delito) y "Tatbestand" (supuesto de hecho o tipo), con lo cual el legislador matiza en cada caso el sentido buscado. En todos ellos se incluye el término "Tat", "hecho", de manera que su significado es perfectamente comprensible como "lo ocurrido", con las variaciones que su uso como prefijo o como sufijo sugiere, pero ya como acepciones jurídicas añadidas al "hecho", que vendría a ser lo que se declara probado en Juicio.

${ }^{4}$ Se ha usado como texto base para la traducción la versión del StGB vigente que ofrece en internet el "Ministerio Federal de Justicia y Protección del Consumidor" de Alemania, junto con la "Sociedad Limitada Juris" (www.juris.de), con adición posterior por el traductor de las modificaciones a que se refiere la nota anterior, que no figuran en el mencionado texto, utilizado hasta el mes de Agosto de 2017, y de las que se dará cuenta en los concretos preceptos afectados. Esta ley de modificación entró en vigor el 1 de Julio de 2017.

${ }^{5}$ Abreviatura de "Reichsgesetzblatt", que se podría traducir por Periódico de Publicación de Leyes del Reino.

${ }^{6}$ Abreviatura de "Bundesgesetzblatt", que se podría traducir por Periódico Federal de Publicación de Leyes.

${ }^{7}$ En alemán se utiliza el término "Geltung" para referirse a la vigencia de una disposición, pero también al ámbito espacial en el cual está vigente esa disposición. Por ello, se traduce el rótulo del Título Primero como "Ámbito de aplicación", un término amplio que abarca tanto al espacial como al temporal. Y en el parágrafo 2 se titula "Vigencia temporal".

${ }^{8}$ Es la traslación al StGB del art. 103, II de la Ley Fundamental de Bonn en el que se formula el principio de legalidad de las penas, y el de irretroactividad. Concuerda con el texto del art. $2^{\circ}$, apartado 1 , del Título Preliminar del CP español:
} 


\section{§ 2 Zeitliche Geltung}

(1) Die Strafe und ihre Nebenfolgen bestimmen sich nach dem Gesetz, das zur Zeit der Tat gilt.

(2) Wird die Strafdrohung während der Begehung der Tat geändert, so ist das Gesetz anzuwenden, das bei Beendigung der Tat gilt.

(3) Wird das Gesetz, das bei Beendigung der Tat gilt, vor der Entscheidung geändert, so ist das mildeste Gesetz anzuwenden.

(4) 1. Ein Gesetz, das nur für eine bestimmte Zeit gelten soll, ist auf Taten, die während seiner Geltung begangen sind, auch dann anzuwenden, wenn es außer Kraft getreten ist. 2. Dies gilt nicht, soweit ein Gesetz etwas anderes bestimmt.

(5) Für Einziehung und Unbrauchbarmachung gelten die Absätze 1 bis 4 entsprechend.

(6) Über Maßregeln der Besserung und Sicherung ist, wenn gesetzlich nichts anderes bestimmt ist, nach dem Gesetz zu entscheiden, das zur Zeit der Entscheidung gilt.

\section{$\S 2$ Vigencia en el tiempo ${ }^{9}$}

(1) La pena y sus consecuencias accesorias se determinan con arreglo a la ley vigente al momento del hecho ${ }^{10}$.

(2) Si la amenaza penal cambiara durante la comisión del hecho, será aplicable la ley vigente al momento de finalizar el mismo ${ }^{11}$.

(3) Si cambiara la ley vigente al momento de finalizar el hecho antes de recaer Sentencia, se aplicará la ley más favorable ${ }^{12}$.

(4) 1. Una ley con vigencia para tan solo un determinado periodo de tiempo es también aplicable a hechos cometidos durante su vigencia, aunque se haya derogado. 2. Esto no rige si una ley dispone algo distinto.

(5) Para la confiscación y la inutilización ${ }^{13}$, rigen los párrafos 1 a 4.

(6) Si no se dispone otra cosa por la ley, se decidirá acerca de las medidas de seguridad y mejora por la ley vigente al momento de la Sentencia ${ }^{14}$.

\footnotetext{
${ }^{9}$ Se consagra aquí la interdicción de la analogía y la aplicación obligatoria de la ley más favorable. Redacción conforme a la Ley para la reforma de expropiaciones patrimoniales (Vermögensabschöpfung) de 13 de abril de 2017 (BGBI. I S. 872), en vigor desde el 1 de Julio de 2017.

10 Se corresponde con el art. 2.1, inciso primero, del CP español.

11 Se corresponde con el art. 2.2, incisos primero y segundo del CP español.

${ }^{12}$ Concuerda también con el art. $2^{\circ} .2$, incisos primero y segundo, del CP español.

13 La "confiscación" se refiere a los réditos o ganancias obtenidos mediante la comisión del delito, y la "inutilización" es una forma de comiso referida específicamente a escritos o papeles cuya divulgación intencionada daría lugar a la comisión de un delito. V. $§ 74 \mathrm{c}$, d y e. Antes de la reforma también existía el "comiso" referido a objetos utilizados en el delito,

${ }^{14}$ Concuerda con el art. 2.1 y 2.2 del CP español.
} 


\section{§ 3 Geltung für Inlandstaten}

Das deutsche Strafrecht gilt für Taten, die im Inland begangen werden.

\section{§ 4 Geltung für Taten auf deutschen Schiffen und Luftfahrzeugen}

Das deutsche Strafrecht gilt, unabhängig vom Recht des Tatorts, für Taten, die auf einem Schiff oder in einem Luftfahrzeug begangen werden, das berechtigt ist, die Bundesflagge oder das Staatszugehörigkeitszeichen der Bundesrepublik Deutschland zu führen.

\section{§ 3 Vigencia para hechos cometidos en el territorio ${ }^{15}$}

El derecho penal alemán rige para los hechos cometidos en el territorio.

\section{§ 4 Vigencia para hechos cometidos en barcos $y$ aeronaves alemanes ${ }^{16}$}

El Derecho penal alemán rige, con independencia del lugar del hecho, para hechos cometidos en un barco o aeronave con derecho a ostentar la bandera federal 0 los símbolos correspondientes a la República Federal de Alemania.

\section{§ 5 Auslandstaten mit besonderem Inlandsbezug}

Das deutsche Strafrecht gilt, unabhängig vom Recht des Tatorts, für folgende Taten, die im Ausland begangen werden:

1. Weggefallen

2. Hochverrat (§§ 81 bis 83 );

3. Gefährdung des demokratischen Rechtsstaates

\section{§ 5 Hechos cometidos en el extranjero con especial vinculación con el territorio. $^{17}$}

El Derecho penal alemán rige, independientemente del Derecho del lugar del hecho, para los siguientes hechos cometidos en el extranjero:

1. Derogado.

2. Alta traición (§§ 81 a 83);

3. Puesta en peligro del Estado democrático de Derecho ${ }^{18}$

\footnotetext{
${ }^{15}$ El término alemán "Inland", "territorio del Estado", "patria", o en su caso "tierra firme"- que aquí se traduce simplemente por "territorio"- se refiere al ámbito jurídico de aplicación del Derecho alemán en el territorio del Estado para establecer la diferencia con otros ámbitos de vigencia territorial establecidos en todos los países a través de la ficción de territorio que abarca a las aeronaves y los barcos con pabellón nacional. Para abreviar se traduce simplemente por "territorio", pues queda claro que se trata del territorio de la República Federal de Alemania y ello no se especifica en el texto original por las mismas y obvias razones. Este precepto se corresponde con el art. 23.1 de la LOPJ.

${ }^{16} \mathrm{Al}$ igual que el anterior este precepto se corresponde con el art. 23.1 de la LOPJ.

17 Este precepto trata de la extraterritorialidad, y se correspondería -con las peculiaridades propias de cada país- con los arts. 23.2 y ss. de la LOPJ, algunos de cuyos apartados $-2,4$ y 5 - se han modificado en el año 2014 por la Ley Orgánica 1/2014, de 13 de marzo, de modificación de la Ley Orgánica 6/1985, de 1 de julio, del Poder Judicial, relativa a la justicia universal; por lo tanto la modificación se ha producido poco tiempo después de la anterior reforma, de 2009, ahora con la finalidad de atemperar o dotar de mayor realismo la afirmación de competencia jurisdiccional de los Tribunales españoles respecto de hechos cometidos fuera del territorio nacional, y sobre todo someterse a los Tratados internacionales. Así, en la Exposición de Motivos, se afirma: "Ese es el sentido que inspira la reforma que ahora se lleva a cabo, delimitar con claridad, con plena aplicación del principio de legalidad y reforzando la seguridad jurídica, los supuestos en que la jurisdicción española puede investigar y conocer de delitos cometidos fuera del territorio en que España ejerce su soberanía".

18 Llama la atención que a pesar de la acepción constitucional del Estado alemán como "Estado federal, social y democrático de Derecho", en el art. 20 de la Ley Fundamental de Bonn, este precepto del StGB solo se refiera a "Estado democrático de Derecho", por tanto, no se omiten en la traducción sino en el propio texto.
} 
a) in den Fällen der $\S \S 89$, 90a Abs. 1 und des $\S 90 b$, wenn der Täter Deutscher ist und seine Lebensgrundlage im räumlichen Geltungsbereich dieses Gesetzes hat, und

b) in den Fällen der $\S \S 90$ und 90 a Abs. 2;

4. Landesverrat und Gefährdung der äußeren Sicherheit (§§ 94 bis 100a);

5. Straftaten gegen die Landesverteidigung

a) in den Fällen der $\S \S 109$ und $109 \mathrm{e}$ bis $109 \mathrm{~g}$ und

b) in den Fällen der §§ 109a, 109d und 109h, wenn der Täter Deutscher ist und seine Lebensgrundlage im räumlichen Geltungsbereich dieses Gesetzes hat;

6. Straftaten gegen die persönliche Freiheit

a) ) in den Fällen der §§ 234a und 241a, wenn die Tat sich gegen eine Person richtet, die zur Zeit der Tat Deutsche ist und ihren Wohnsitz oder gewöhnlichen Aufenthalt im Inland hat,

b) b) in den Fällen des $\S 235$ Absatz 2 Nummer 2, wenn die Tat sich gegen eine Person richtet, die zur Zeit der Tat ihren Wohnsitz oder gewöhnlichen Aufenthalt im Inland hat, und

c) c) in den Fällen des $\S 237$, wenn der Täter zur Zeit der Tat Deutscher ist oder wenn die Tat sich gegen eine Person richtet, die zur Zeit der Tat ihren Wohnsitz oder a) En los casos de los $\S \S 89$, $90 a$ pár. 1 y del $\S 90$ b, cuando el autor sea alemán y su medio vital ${ }^{19}$ se encuentre en el ámbito de vigencia espacial de esta ley, y

b) En los casos de los $\S \S 90$ y 90 a, pár. 2;

4. Traición al Estado y puesta en peligro de la seguridad exterior (§§ 94 a 100a);

5. Delitos contra la defensa del Estado

a) en los casos de los $\S \S$ 109 y $109 \mathrm{e}$, a $109 \mathrm{~g}$, y

b) en los casos de los $\S \S$ 109a, 109d, y 109 h, cuando el autor sea alemán y su medio vital se encuentre en el ámbito de vigencia territorial de esta ley ${ }^{20}$;

6. Delitos contra la libertad personal

a) en los casos de los $\S \S$ $234 a$, y $241 a$, cuando el hecho se dirija contra una persona que al momento del hecho sea alemán y tenga su domicilio o residencia habitual en el territorio, y

b) en los casos del $\S 235$, párrafo 2, número 2 , cuando el hecho se dirija contra una persona que al momento del hecho sea alemán y tenga su domicilio o residencia habitual en el territorio, $y$

c) en los casos del $\S 237$ cuando el autor al momento del hecho sea alemán, o cuando el hecho se dirija contra una persona que en ese momento tenga su

\footnotetext{
19 He traducido "Lebensgrundlage" por "medio vital", no por "medios de vida" porque estos se entienden en un sentido económico como "medios de/para ganarse la vida", mientras que "medio vital" vendría a ser el conjunto de situaciones y relaciones que constituyen el "medio ambiente vital" de un individuo, que también incluyen, pero no únicamente, sus "medios de vida". Véase también, el § 89a, (3).

${ }^{20}$ Véase supra, n. 10.
} 
gewöhnlichen Aufenthalt im Inland hat;

7. Verletzung von Betriebs- oder Geschäftsgeheimnissen eines im räumlichen Geltungsbereich dieses Gesetzes liegenden Betriebs, eines Unternehmens, das dort seinen Sitz hat, oder eines Unternehmens mit Sitz im Ausland, das von einem Unternehmen mit Sitz im räumlichen Geltungsbereich dieses Gesetzes abhängig ist und mit diesem einen Konzern bildet;

8. Straftaten gegen die sexuelle Selbstbestimmung in den Fällen des $\S 174$ Absatz 1, 2 und 4, der $\S \S 176$ bis 178 und des $\S 182$, wenn der Täter zur Zeit der Tat Deutscher ist;

9. Straftaten gegen das Leben:

a) in den Fällen des $\S 218$ Absatz 2 Satz 2 Nummer 1 und Absatz 4 Satz 1, wenn der Täter zur Zeit der Tat Deutscher ist, und

b) in den übrigen Fällen des $\S 218$, wenn der Täter zur Zeit der Tat Deutscher ist und seine Lebensgrundlage im Inland hat;

9a Straftaten gegen die körperliche Unversehrtheit

a) in den Fällen des $\S 226$ Absatz 1 Nummer 1 in Verbindung mit Absatz 2 bei Verlust der Fortpflanzungsfähigkeit, wenn der Täter zur Zeit der Tat Deutscher ist, und

b) in den Fällen des $\S 226 a$, wenn der Täter zur Zeit der Tat Deutscher ist oder wenn die Tat sich gegen eine Person richtet, die zur Zeit der Tat ihren Wohnsitz oder domicilio o residencia habitual en el territorio;

7. Violación de secretos de empresa o negocio, de una empresa que se encuentre en el ámbito territorial de esta ley, de una empresa que tenga en el mismo su sede, o de una empresa con sede en el extranjero que dependa de otra con sede en el ámbito territorial de esta ley y con la cual forme un consorcio ${ }^{21}$.

8. Delitos contra la libertad sexual en los casos del $\S 174$, párrafos 1,2 y 4 , de los $\S \S 176$ a 178, y del $\S 182$, cuando el autor al momento del hecho sea alemán;

9. Delitos contra la vida

a) en los casos del $\S 218$, párrafo 2, inciso 2, número 1 y párrafo 4 , inciso 1 , cuando el autor al momento del hecho sea alemán, y

b) en los demás casos del § 218, cuando el autor al momento del hecho sea alemán y tenga su medio vital en el territorio;

9a: Delitos contra la inviolabilidad personal

a) en los casos del $\S 226$, párrafo 1 , número 1 , en relación con el párrafo 2 si hay pérdida de la fertilidad, cuando el autor al momento del hecho sea alemán, y

b) en los casos del $\S 226 a$, cuando el autor al momento del hecho sea alemán o cuando el hecho se dirija contra una persona que al momento del hecho tenga su

\footnotetext{
${ }^{21}$ Se utiliza la alocución "consorcio", aunque quizá fuera también válido "grupo de empresas", como significado en mi opinión más cercano al término alemán "Konzern": grupo de empresas con una empresa dirigente y otras reunidas a su alrededor, dependientes de ella, pero con una al menos formal independencia jurídica y de gestión económica -no dirección- propia. En definitiva, se trata de un término de Derecho mercantil al cual habrá que remitirse en la interpretación del precepto, pues no parece existir otro término en español para Konzern.
} 
gewöhnlichen Aufenthalt

im Inland hat;

10. Falsche uneidliche Aussage, Meineid und falsche Versicherung an Eides Statt (§§ 153 bis 156) in einem Verfahren, das im räumlichen Geltungsbereich dieses Gesetzes bei einem Gericht oder einer anderen deutschen Stelle anhängig ist, die zur Abnahme von Eiden oder eidesstattlichen Versicherungen zuständig ist;

11. Straftaten gegen die Umwelt in den Fällen der $\S \S 324,326,330$ und 330a, die im Bereich der deutschen ausschließlichen Wirtschaftszone begangen werden, soweit völkerrechtliche Übereinkommen zum Schutze des Meeres ihre Verfolgung als Straftaten gestatten;

11a Straftaten nach $\S 328$ Abs. 2 Nr. 3 und 4 , Abs. 4 und 5, auch in Verbindung mit $\S 330$, wenn der Täter zur Zeit der Tat Deutscher ist;

12. Taten, die ein deutscher Amtsträger oder für den öffentlichen Dienst besonders Verpflichteter während eines dienstlichen Aufenthalts oder in Beziehung auf den Dienst begeht;

13. Taten, die ein Ausländer als Amtsträger oder für den öffentlichen Dienst besonders Verpflichteter begeht;

14. Taten, die jemand gegen einen Amtsträger, einen für den öffentlichen Dienst besonders Verpflichteten oder einen Soldaten der Bundeswehr während der Ausübung ihres Dienstes oder in Beziehung auf ihren Dienst begeht;

15. Straftaten im Amt nach den §§ 331 bis 337 , wenn

a) der Täter zur Zeit der Tat Deutscher ist,

b) der Täter zur Zeit der Tat Europäischer Amtsträger ist und seine Dienststelle ihren Sitz im Inland hat, domicilio o residencia habitual en el territorio;

10. Falsa declaración, falso testimonio y falsa declaración jurada (§§ 153 a 156) en un procedimiento que tenga lugar en el ámbito territorial de esta ley ante un Tribunal o que dependa de otro órgano alemán, que sea competente para la toma de juramento o declaraciones juradas;

11. Delitos contra el medio ambiente en los casos de los $\S \S 324,326$, 330 y $330 a$, que se cometan en el ámbito de la zona económica exclusiva alemana siempre que se permita su persecución como delitos en los Tratados Internacionales sobre protección de los mares.

11a: Delitos según el $\S 328$, párrafo 2 , números 3 y 4 , párrafo 4 y 5 , también en relación con el $\S 330$, cuando el autor al momento del hecho sea alemán;

12. Hechos cometidos por un funcionario alemán o por alguien especialmente obligado por el servicio público durante una estancia de servicio o en relación con el servicio

13. Hechos cometidos por un extranjero como funcionario 0 especialmente obligado por el servicio público;

14. Hechos cometidos contra un funcionario 0 persona especialmente obligada por el servicio público o contra un soldado del Ejército Federal durante el ejercicio de, o en relación con, su deber.

15. Delitos cometidos durante el ejercicio de su función según los $\S \S 331$ a 337 , cuando

a) el autor al momento del hecho sea alemán

b) el autor al momento del hecho sea funcionario europeo y su puesto 
c) die Tat gegenüber einem Amtsträger, einem für den öffentlichen Dienst besonders Verpflichteten oder einem Soldaten der Bundeswehr begangen wird oder

d) die Tat gegenüber einem Europäischen Amtsträger oder Schiedsrichter, der zur Zeit der Tat Deutscher ist, oder einer nach § $335 a$ gleichgestellten Person begangen wird, die zur Zeit der Tat Deutsche ist;

16. Bestechlichkeit und Bestechung von Mandatsträgern (§ 108e), wenn

a) a) der Täter zur Zeit der Tat Mitglied einer deutschen Volksvertretung oder Deutscher ist oder

b) b) die Tat gegenüber einem Mitglied einer deutschen

Volksvertretung oder einer Person, die zur Zeit der Tat Deutsche ist, begangen wird;

17. Organ- und Gewebehandel ( $§ 18$ des Transplantationsgesetzes), wenn der Täter zur Zeit der Tat Deutscher ist.

\section{$\S 6$ Auslandstaten gegen international geschützte Rechtsgüter}

Das deutsche Strafrecht gilt weiter, unabhängig vom Recht des Tatorts, für folgende Taten, die im Ausland begangen werden:

1. (weggefallen)

\begin{abstract}
tenga su sede en el territorio

c) el hecho se haya cometido contra un funcionario, contra una persona especialmente obligada por el servicio o un soldado del Ejército Federal, o
\end{abstract}

d) el hecho se haya cometido contra un funcionario europeo o árbitro que al momento del hecho sea alemán, o contra una persona asimilada con arreglo al § 335 a, que al momento del hecho sea alemán.

16. Corrupción y soborno de representantes políticos $(\S 108$ e) cuando

a) el autor al momento del hecho sea miembro de una institución alemana de representación política, o sea alemán, o

b) el hecho se cometa contra un miembro de una institución alemana de representación política, o contra una persona que al momento del hecho sea alemana;

17. Comercio de órganos o tejidos ( $\S$ 18 de la ley de transplantes) cuando el autor al momento del hecho sea alemán.

\section{§ 6 Hechos cometidos en el extranjero contra bienes jurídicos protegidos internacionalmente ${ }^{22}$}

El Derecho penal alemán rige, independientemente del Derecho del lugar del hecho, para los siguientes hechos cometidos en el extranjero:

1. (suprimido)

\footnotetext{
${ }^{22} \mathrm{Al}$ igual que el precepto anterior, concierta con el art. 23. 2 y ss. [en especial 4, p)] de la LOPJ.
} 
2. Kernenergie-, Sprengstoff- und Strahlungsverbrechen in den Fällen der $\S \S 307$ und 308 Abs. 1 bis 4 , des $\S 309$ Abs. 2 und des § 310;

3. Angriffe auf den Luft- und Seeverkehr (§ 316c);

4. Menschenhandel (§ 232);

5. unbefugter Vertrieb von Betäubungsmitteln;

6. verbreitung pornographischer Schriften in den Fällen der $\S \S$ 184a, 184b Absatz 1 und 2 und $\S$ 184c Absatz 1 und 2, jeweils auch in Verbindung mit $\S 184 d$ Absatz 1 Satz 1;

7. Geld- und Wertpapierfälschung (§§ 146, 151 und 152), Fälschung von Zahlungskarten mit Garantiefunktion und Vordrucken für Euroschecks (§ 152b Abs. 1 bis 4) sowie deren Vorbereitung ( $\S \S 149,151,152$ und 152b Abs. 5);

8. Subventionsbetrug ( $(264)$;

9. Taten, die auf Grund eines für die Bundesrepublik Deutschland verbindlichen

zwischenstaatlichen

Abkommens auch dann zu verfolgen sind, wenn sie im Ausland begangen werden.

\section{§ 7 Geltung für Auslandstaten in anderen Fällen}

(1) Das deutsche Strafrecht gilt für Taten, die im Ausland gegen einen Deutschen begangen werden, wenn die Tat am Tatort mit Strafe bedroht ist oder der Tatort keiner Strafgewalt unterliegt.

(2) Für andere Taten, die im Ausland begangen werden, gilt das deutsche Strafrecht, wenn die Tat am Tatort mit Strafe bedroht ist oder der Tatort keiner Strafgewalt unterliegt und wenn der Täter

1. zur Zeit der Tat Deutscher war oder es
2. Delitos relativos a la energía nuclear, explosivos y radiaciones en los casos de los $\S \S 307$ y 308 párrafos 1 a 4 , del $\S 309$ párrafo 2 y del $\S 310$;

3. Ataques al tráfico aéreo y marítimo (§ 316c);

4. Tráfico de personas ( $\S 232)$;

5. Comercio ilícito con estupefacientes;

6. Divulgación de textos pornográficos en los casos de los $\S \S 184 a, 184 b$ párrafos 1 y 2 , y $\S$ 184c párrafos 1 y 2 , en relación, en su caso, con el $\S 184 d$ párrafo 1 inciso 1;

7. Falsificación de moneda y valores (§§ 146, 151 y 152), Falsificación de tarjetas y Eurocheques ( $\S 152 \mathrm{~b}$ párrafo. 1 bis 4) así como su preparación (§§ 149, 151, 152 y 152b párrafo 5);

8. Estafa de subvenciones ( $(264)$;

9. Hechos que de acuerdo con un Convenio vinculante suscrito para la República Federal de Alemania deben ser perseguidos también cuando se cometan en el extranjero.

\section{\$ 7 Vigencia para hechos cometidos en el extranjero, en otros casos. ${ }^{23}$}

(1) El Derecho penal alemán rige para hechos cometidos en el extranjero contra un alemán, si en el lugar de comisión el hecho está penado, o si a dicho lugar no subyace jurisdicción penal alguna.

(2) Para otros hechos cometidos en el extranjero rige el Derecho penal alemán, si en el lugar de comisión el hecho está penado, o si a dicho lugar no subyace jurisdicción penal alguna y si el autor

1. al momento del hecho fuera

\footnotetext{
23 Este precepto puede considerarse una continuación del anterior, referido ahora a supuestos
} residuales. 
nach der Tat geworden ist oder

2. zur Zeit der Tat Ausländer war, im Inland betroffen und, obwohl das Auslieferungsgesetz seine Auslieferung nach der Art der Tat zuließe, nicht ausgeliefert wird, weil ein Auslieferungsersuchen innerhalb angemessener Frist nicht gestellt oder abgelehnt wird oder die Auslieferung nicht ausführbar ist.

\section{§ 8 Zeit der Tat}

Eine Tat ist zu der Zeit begangen, zu welcher der Täter oder der Teilnehmer gehandelt hat oder im Falle des Unterlassens hätte handeln müssen. Wann der Erfolg eintritt, ist nicht maßgebend.

\section{$\S 9$ Ort der Tat}

(1) Eine Tat ist an jedem Ort begangen, an dem der Täter gehandelt hat oder im Falle des Unterlassens hätte handeln müssen oder an dem der zum Tatbestand gehörende Erfolg eingetreten ist oder nach der Vorstellung des Täters eintreten sollte.

(2) Die Teilnahme ist sowohl an dem Ort begangen, an dem die Tat begangen ist, als auch an jedem Ort, an dem der Teilnehmer gehandelt hat oder im Falle des Unterlassens hätte handeln müssen oder an dem nach seiner Vorstellung die Tat begangen werden sollte. Hat der Teilnehmer an einer Auslandstat alemán o llegara a serlo tras el hecho o

2. al momento del hecho fuera extranjero, resultase afectado por el hecho en el territorio, y aunque la Ley de extradición admitiera su extradición por la clase de hecho, no sea extraditado porque no se haya promovido en el plazo debido una demanda de extradición, o se haya denegado, o la extradición no sea viable.

\section{§ 8 Momento del hecho ${ }^{24}$}

Un hecho se comete en el momento en el que el autor o el partícipe ha actuado, o en caso de omisión, hubiera debido actuar. No es decisivo cuándo se produce el resultado.

\section{§ 9 Lugar del hecho ${ }^{25}$}

(1) Un hecho se comete en el lugar en el que el autor haya actuado o, en caso de omisión, hubiera debido actuar, o en el que se haya producido el resultado propio del supuesto de hecho, o en el que según la representación del autor debió producirse.

(2) La participación se produce tanto en el lugar en el que se ha cometido el hecho como en el lugar en el que el partícipe haya actuado, o en caso de omisión hubiera debido actuar, o en el que según la representación del autor debió haberse producido. Si el partícipe actuó dentro del

\footnotetext{
${ }^{24}$ Este precepto concierta con el art. 7 del CP español, si bien con ciertas diferencias como la referencia en el § 8 al partícipe -no solo al autor- o la advertencia de que no es decisivo, y por tanto no se usará como criterio de determinación del momento de comisión el de producción del resultado.

25 A la vista de lo dispuesto en el art. 23.1 LOPJ todo indica -contrario sensu- que no se establece en la legislación penal española qué se entiende por lugar de comisión del hecho, a pesar de la relevancia que puede albergar este dato como se aprecia en lo previsto en el $\S 7$ donde el legislador penal alemán sí aplica la cláusula residual de entender competente el Derecho penal alemán en ausencia de competencia de otro Estado, o si la autoridad del territorio donde se cometiera el delito no interviene. Es destacable de nuevo la referencia a los partícipes, y no solo al autor de los hechos en el § 9 (2).
} 
im Inland gehandelt, so gilt für die Teilnahme das deutsche Strafrecht, auch wenn die Tat nach dem Recht des Tatorts nicht mit Strafe bedroht ist. territorio en un hecho cometido en el extranjero, rige para la participación el Derecho penal alemán, incluso si el hecho de acuerdo con el Derecho del lugar de comisión no está amenazado con pena.

\section{$\S 10$ Sondervorschriften für $\S 10$ Reglas especiales para menores Jugendliche und Heranwachsende $\quad$ jóvenes $^{26}$}

Für Taten von Jugendlichen und Heranwachsenden gilt dieses Gesetz nur, soweit im Jugendgerichtsgesetz nichts anderes bestimmt ist.

Esta ley rige para hechos cometidos por menores y jóvenes, siempre que en la Ley de Tribunales de Menores no se disponga lo contrario.

Zweiter Titel. Sprachgebrauch

\section{$\S 11$ Personen und Sachbegriffe}

(1) Im Sinne dieses Gesetzes ist

1. Angehöriger: wer zu den folgenden Personen gehört:

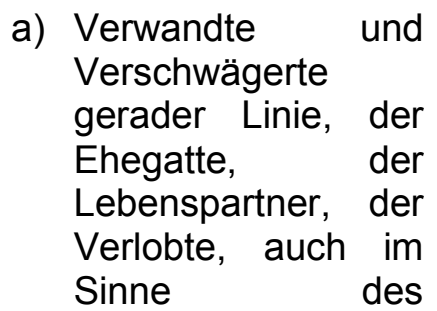

Título Segundo. Terminología

\section{\$11 Concepto de personas y cosas $^{27}$}

(1) A los efectos de esta ley,

1. Concurre parentesco en quien sea alguna de estas personas:

a) Familiares $y$ afines en línea recta, cónyuge, el conviviente, el prometido, también en el

\footnotetext{
${ }^{26}$ Este precepto concierta con el art. 19 del CP español, y los arts. 1.1 (contrario sensu) y 5, de la Ley Orgánica 5/2000, de 12 de enero, reguladora de la responsabilidad penal de los menores. Véase el $\S 1$ de la Ley alemana de Tribunales de Menores, según la cual el "menor" tiene más de 14 y menos de 18, y el "joven" más de 18 y menos de 21.

${ }_{27}$ Redactado conforme a la Ley para la reforma de la expropiación patrimonial de 13 de abril de 2017 (BGBI. I S. 872), en vigor desde el 1 de Julio de 2017. Este precepto cumple una función de regla general que después se concretará en los delitos en particular, si bien en la consideración de si ello agrava o atenúa o hay especificidades, se pueden producir contradicciones dentro de la misma ley. Por otro lado, no parece lógico que se considere, por ejemplo, al/la prometido/a como pariente con carácter general, a menos que se defina también qué es, lo cual raya en el absurdo. En cualquier caso, parece que concierta el párrafo 1, a) y b) con los arts. 23 y 268 del CP español. Algo parecido sucede con los conceptos de Derecho administrativo "cargo público", "funcionario", "Juez", etc., pues se definen, o más bien se enumeran, los que a los efectos del StGB lo son, lo cual, o bien puede plantear verdaderos problemas de lagunas de aplicación, o bien entrar en conflicto con los sujetos designados en preceptos concretos como "Autoridad", "funcionario". En el CP se recoge -a efectos penales- el concepto de Autoridad en el art. 24.1, y el de funcionario en el art. 24.2. Por otro lado, afirma el principio de legalidad de la antijuridicidad penal al referirla a los tipos penales en el párrafo 5., lo cual se antoja superfluo, o al menos mueve a preguntarse si será una regla para la resolución de los concursos de leyes. A continuación, advierte que no solo la consumación sino también la tentativa es punible, y qué se entiende por "medidas" y por "compensación".
} 
Lebenspartnerschaft sgesetzes,

Geschwister,

Ehegatten oder

Lebenspartner der

Geschwister,

Geschwister der

Ehegatten oder

Lebenspartner, und

zwar auch dann,

wenn die Ehe oder

die

Lebenspartnerschaft

welche die

Beziehung

begründet hat, nicht

mehr besteht oder

wenn

die

Verwandtschaft oder

Schwägerschaft

erloschen ist,

b) Pflegeeltern und Pflegekinder;

2. Amtsträger: wer nach deutschem Recht

a) Beamter oder Richter ist,

b) in einem sonstigen öffentlichrechtlichen

Amtsverhältnis steht oder

c) sonst dazu bestellt ist, bei einer Behörde oder bei einer sonstigen

Stelle oder in deren

Auftrag Aufgaben

der öffentlichen

Verwaltung

unbeschadet der zur

Aufgabenerfüllung

gewählten

Organisationsform

wahrzunehmen; sentido de la

Ley de

convivientes de

hecho, los

hermanos, los

cónyuges 0

convivientes de

los hermanos,

los hermanos

de los

cónyuges $\mathrm{O}$

convivientes, y

también

cuando el

matrimonio o la

convivencia de

hecho que se

estableciera

por la relación

ya no exista o

cuando el

parentesco 0

afinidad se

haya

extinguido,

b) Padres e hijos

en

acogimiento;

2. Es cargo público: quien según el Derecho alemán

a) sea

Funcionario o Juez,

b) se encuentre en alguna otra relación

funcionarial jurídico-pública 0

c) esté designado por una

Autoridad o por otro cargo, o por cuyo encargo debe realizar

funciones de la Administración pública sin perjuicio de la forma organizativa que se haya elegido para 
$2 a$

Europäischer

Amtsträger: wer

a) Mitglied Europäischen

Kommission, der

Europäischen

Zentralbank, des

Rechnungshofs

oder eines Gerichts

der Europäischen

Union ist,

b) Beamter oder sonstiger

Bediensteter der

Europäischen Union

oder einer auf der

Grundlage des

Rechts der

Europäischen Union geschaffenen

Einrichtung ist oder

c) mit der

Wahrnehmung von

Aufgaben der

Europäischen Union oder von Aufgaben

einer auf der

Grundlage des

Rechts der

Europäischen Union

geschaffenen

Einrichtung

beauftragt ist;

3. Richter: wer nach deutschem Recht Berufsrichter oder ehrenamtlicher Richter ist;

4. für den öffentlichen Dienst besonders Verpflichteter: wer, ohne Amtsträger zu sein,

a) bei einer Behörde oder bei einer sonstigen Stelle, die Aufgaben der öffentlichen

Verwaltung wahrnimmt, oder

b) bei einem Verband ejercer dichas

funciones;

2a Es cargo público europeo: quien

a) sea miembro de la Comisión

Europea, del

Banco Central

Europeo, del

Tribunal de

Cuentas

Europeo o de un Tribunal de la Unión

Europea,

b) sea funcionario u otra persona al servicio de la Unión Europea o de una institución constituida sobre la base del Derecho de la Unión Europea o

c) haya recibido el encargo de ejercer competencias de la Unión Europea o de una institución constituida sobre la base del Derecho de la Unión Europea;

3. Es Juez, quien de acuerdo con el Derecho alemán es Juez de carrera o Juez honorario;

4. Está especialmente obligado por el servicio público: quien sin ser cargo público,

a) ejerce funciones de la Administración pública para una Autoridad u otro cargo, o

b) para un 


$\begin{array}{lr}\text { Oder } & \text { sonstigen } \\ \text { Zusammenschluß, } \\ \text { Betrieb r } & \text { oder } \\ \text { Unternehmen, } & \text { die } \\ \text { für eine } & \text { Behörde } \\ \text { oder für } & \text { eine } \\ \text { sonstige } & \text { Stelle } \\ \text { Aufgaben r der } \\ \text { öffentlichen } & \\ \text { Verwaltung } & \\ \text { ausführen, }\end{array}$

beschäftigt oder für sie tätig und auf die gewissenhafte Erfüllung seiner Obliegenheiten auf Grund eines Gesetzes förmlich verpflichtet ist;

5. rechtswidrige Tat: nur eine solche, die den Tatbestand eines Strafgesetzes verwirklicht;

6. Unternehmen einer Tat deren Versuch und deren Vollendung;

7. Behörde: auch ein Gericht;

8. Maßnahme: jede Maßregel der Besserung und Sicherung, der Verfall, die Einziehung und die Unbrauchbarmachung;

9. Entgelt: jede in einem Vermögensvorteil bestehende Gegenleistung.

(2) Vorsätzlich im Sinne dieses Gesetzes ist eine Tat auch dann, wenn sie einen gesetzlichen Tatbestand verwirklicht, der hinsichtlich der Handlung Vorsatz voraussetzt, hinsichtlich einer dadurch verursachten besonderen Folge jedoch Fahrlässigkeit ausreichen läßt.

(3) Den Schriften stehen Ton- und Bildträger, Datenspeicher, Abbildungen und andere Darstellungen in denjenigen Vorschriften gleich, die auf diesen
colectivo u otra asociación, negocio 0 empresa que ejerce funciones para una Autoridad u otro cargo de la
Administración pública,

esté empleado o actúe para ella ${ }^{28}$, y esté formalmente obligado por una ley al escrupuloso cumplimiento de sus obligaciones;

5. Es un hecho antijurídico: solo el que coincida con el supuesto de hecho de una ley penal;

6. Realizar un hecho: lo es su tentativa y su consumación;

7. Autoridad: también lo es un Tribunal;

8. Medidas: Io son las de Seguridad y Mejora, la confiscación, y la inutilización;

9. Compensación: lo es toda contraprestación consistente en una ventaja patrimonial.

(2) También es doloso un hecho a los efectos de esta ley, cuando coincida con un supuesto de hecho legal que presuponga el dolo para la acción, pero que, en relación con una determinada consecuencia causada a través de aquella, baste con la imprudencia.

(3) A los efectos de aquellos preceptos que se remiten a este párrafo, se equipararán los escritos a los soportes de sonido e imágenes, a los

\footnotetext{
${ }^{28}$ No queda claro quién es "ella" de entre los sustantivos femeninos que se mencionan con anterioridad, pero supongo que se trata del último, "la Administración Pública".
} 
Absatz verweisen.

\section{$\S 12$ Verbrechen und Vergehen}

(1) Verbrechen sind rechtswidrige Taten, die im Mindestmaß mit Freiheitsstrafe von einem Jahr oder darüber bedroht sind.

(2) Vergehen sind rechtswidrige Taten, die im Mindestmaß mit einer geringeren Freiheitsstrafe oder die mit Geldstrafe bedroht sind.

(3) Schärfungen oder Milderungen, die nach den Vorschriften des Allgemeinen Teils oder für besonders schwere oder minder schwere Fälle vorgesehen sind, bleiben für die Einteilung außer Betracht. almacenes de datos, a las reproducciones y otras representaciones.

\section{$\S 12$ Delito y Falta ${ }^{29}$}

(1) Delitos son los hechos antijurídicos amenazados con pena privativa de libertad de un año o más.

(2) Faltas son los hechos antijurídicos amenazados con pena privativa de libertad más corta o con multa.

(3) Las agravantes o atenuantes previstas con arreglo a los preceptos de la Parte General, o para casos especialmente graves 0 menos graves, quedan fuera de la anterior clasificación.

\footnotetext{
${ }^{29}$ Se utiliza el término "Falta" conscientemente, a pesar de haber desaparecido como tal del Código Penal español al suprimirse en bloque el Libro Tercero. No obstante, muchas de las antiguas faltas continúan existiendo ahora como "delitos leves" junto a la categoría intermedia de los delitos "menos graves". Por último, una aclaración: en Derecho alemán se diferencia entre Hecho punible (Straftat) e Infracción del orden (Ordnungswidrigkeit). Los hechos punibles se subdividen a su vez en Delitos y Faltas y son los contenidos en el StGB u otras leyes penales. Las Infracciones del orden se contienen en una ley con el mismo nombre -Ordnungswidrigkeitengesetz (OWiG), y son infracciones de índole administrativa, no penal, dado que la competencia para su persecución es de las autoridades administrativas, y por otro lado no se imponen penas por su comisión sino multas administrativas. Debe tenerse en cuenta, no obstante, que puede imponerse por una infracción de ese tipo -de tráfico, en concreto- la prohibición de conducir - $\$ 25$ OWiG- que materialmente es una medida de seguridad coincidente con la retirada del carnet de conducir -§ 61, 5 StGB- de manera que en ocasiones se sitúan dichas infracciones en el límite mismo entre el Derecho administrativo y el Derecho penal.
} 